\title{
nature
}

27 March 2003 Volume 422 Issue no 6930

\section{When the fighting is over...}

The conflict in Iraq has divided world opinion, driving deep wedges even between longstanding allies. In its wake, rebuilding international collaboration will be vital - and in that task, scientists should take a lead.

W ill Saunders, a British astronomer at the Anglo-Australian Observatory in Sydney, left the world in no doubt as to his feelings about the current situation in Iraq. He is one of two protesters arrested for daubing "No war" in huge red letters on the roof of Sydney Opera House (see page 366). In January, 41 Nobel laureates chose a more conventional means of making a similar point, declaring that an attack on Iraq without widespread international support "would undermine, not protect, US security and standing in the world".

Within the broad church of the scientific community, however, there will be those who believe, with equal sincerity, that war is justified to rid the world of a regime that has repeatedly attacked its neighbours and used chemical weapons against its own people. Public statements by pro-war scientists are difficult to find, but some researchers will privately feel that the real villains of the piece are those nations that refused to lend international legitimacy to military intervention. Other scientists will be watching the hostilities unfold in unprecedented detail on their televisions, unsure what to make of it all.

Given this spectrum of opinion, bodies that represent researchers have mostly been silent, realizing that there is no single 'scientific' perspective. Nonetheless, the scientific community should recognize that it has some particular responsibilities, and a huge stake in rebuilding an international consensus. Scientists, after all, helped to develop both the high-tech armaments being used to pursue the assault on Iraq, and the weapons of mass destruction whose alleged possession by Saddam Hussein paved the road to conflict in the first place. Scientists will also play a leading role in verifying claims by the combatants about both types of weapon (see pages 362-363).

More fundamentally, science owes its rapid advancement to the free exchange of ideas and personnel between labs across the globe. Security restrictions introduced by the US administration as part of its 'war on terror' are already impeding this exchange (see Nature 422, 96-97; 2003). If the situation is not now to deteriorate further, scientists must speak out, both to protect progress in their own disciplines and to defend a plethora of international agreements thrashed out under the auspices of the United Nations. The Kyoto Protocol on climate change, the Convention on Biological Diversity, the Chemical Weapons Convention, the Nuclear Non-Proliferation Treaty and others all owe their existence, at least in part, to international scientific collaboration.

The world has much to lose if the current conflict leaves this legal framework, like central Baghdad, in smouldering ruins. Even before the Iraqi crisis came to a head, President George W. Bush's administration had shown itself to be no lover of international agreements. Now, having split so acrimoniously from many of its traditional allies, there is a danger that the world's only superpower may decide that there is little to be gained by working with the United Nations. And that could, in turn, give rise to a highly dangerous situation in which nations and religious factions jostle freely in pursuit of their own interests.

Instead, we must hope that an international consensus can be rebuilt, if falteringly at first. Scientific organizations have not had much to contribute to the debate running up to this war. But in its aftermath, they should speak up loud and clear to press for internationalism in a world that could otherwise veer towards factionalism and further conflict.

\section{In praise of good mentors}

Scientific mentoring gets less recognition than it deserves, not least for its potential in helping researcher minority groups.

T he fog of war last week obscured something positive that President George W. Bush's administration was trying to promote - the recognition of outstanding scientific mentors. Ten individuals and six institutions were honoured last week in the 2002 Presidential Awards for Excellence in Mathematics, Science and Engineering Mentoring at a White House ceremony.

Mentoring as a component of one's scientific career is one of those things that most would agree are positive — at least in the abstract. But mentoring, in the concrete, is rarely recognized beyond the gratitude of the young scientists towards a senior figure who (unless they were unlucky in their choice of laboratory) helped them to publish their first paper or land their first faculty position.

The ten awardees have made a welcome escape from this vacuum of recognition. Perhaps more importantly, their efforts show that seemingly intractable problems in the make-up of the scientific and technological workforce can be addressed. For example, Robert Gray, one of the awardees, guided 11 female students towards $\mathrm{PhDs}$ in his electrical engineering programme at Stanford University over 16 years (for information on more awardees, see www.nsf.gov). In the same time period, 16 men in the programme received the degree. Gray's results - and his recognition for achieving them — are notable because the rate of female representation among his doctoral graduates is almost four times the norm in engineering. According to the US National Science Foundation's Science and Engineering Indicators 2002, engineering has the lowest representation of women - about $10 \%$ in all.

Gray's success on a small scale begs the question of what more successful mentoring could do on a larger scale — particularly for women and minorities. Despite progress, both groups are still highly underrepresented in science, according to recent reports. In the United States, for example, blacks, hispanics and native Americans together make up only $7 \%$ of the scientific academic workforce, even though they represent $24 \%$ of the population, according to the US National Science Foundation's indicators. And men far outnumber women in the physical sciences, according to the International Union of Pure and Applied Physics, which last year published a report on gender disparity.

Recognizing mentors through awards such as those presented last week is one way to encourage scientists to give guidance to their younger colleagues - and also points young scientists towards outstanding labs. Similar recognition by scientific societies and other governments could thrust mentoring further into the spotlight and help to solve some social problems in the process. 